\title{
EFEITOS DE DIFERENTES FONTES DE MATERIAL ORGÂNICO NA FERTILIDADE E UMIDADE DO SOLO
}

\author{
EFFECTS OF DIFFERENT ORGANIC MATERIAL SOURCES ON SOIL FERTILITY AND \\ MOISTURE \&
}
EFECTOS DE DIFERENTES FUENTES DE MATERIALES ORGÁNICOS SOBRE LA FERTILIDAD Y LA HUMEDAD DEL SUELO \&

Recebido em: 04/11/2021 - Aprovado em: 10/12/2021 - Publicado em: 17/12/2021

doi) http://dx.doi.org/10.18011/bioeng2021v15n4p644-659

Daniela Fernanda Alves' (alvesdaniela784@gmail.com)

Kleso Silva Franco Junior ${ }^{1}$ (kleso.junior@yahoo.com.br)

Giselle Prado Brigante1 (giselle.brigante@gmail.com)

Márcio de Souza Dias² (marciodesouzadias2013@gmail.com)

Natália Scalco Ferreira ${ }^{3}$ (nataliascalc085@gmail.com)

\footnotetext{
${ }^{1}$ Centro Superior de Ensino e Pesquisa (CESEP) / Machado, Minas Gerais, Brasil.

2 Secretaria de Estado de Educação de Minas Gerais (SEE-MG), Serrania, Minas Gerais, Brasil.

${ }^{3}$ Instituto Federal do Sul de Minas (IFSULDEMINAS) / Campus Machado, Machado, MG, Brasil.
}

O solo é um recurso de fundamental importância para a agricultura, sendo uma de suas funções o fornecimento equilibrado de nutrientes às plantas. Uma das formas de tornar o solo sustentável é por meio da aplicação de matéria orgânica, que pode ser de origem animal ou vegetal. O objetivo foi avaliar o efeito da adição de diferentes materiais orgânicos ao solo em relação à sua fertilidade e umidade. Realizou uma análise inicial para analisar a fertilidade do solo. Em seguida, a área foi dividida em parcelas e aplicados os tratamentos, que consistiram de 40 ton ha- ${ }^{-1}$ de esterco bovino, 5 ton ha ${ }^{-1}$ de esterco de aviário, 53 ton ha ${ }^{-1}$ de esterco de suíno, 30 ton ha ${ }^{-1}$ de palha de café e 0 ton ha-1 matéria orgânica (controle), sendo estes tratamentos organizados em blocos casualizados com 5 repetições. Após 90 dias, amostras foram retiradas desse solo para análise de fertilidade e umidade. Os tratamentos que mais contribuíram para sua fertilidade foram os dejetos de suínos e bovinos e o que mais reteve a umidade foi a palha de café.

Palavras-chave: Estrume. Nutrientes. Resíduo. Retenção de água. 


\section{INTRODUÇÃO}

Entender as características de cada tipo de solo é fundamental para auxiliar na aptidão e manejos empregados visando a produção sustentável de alimentos a sociedade. Em relação ao Brasil, o país apresenta solos bem diversificados em razão a elevada extensão territorial, da grande diversidade de ambientes e dos seus fatores de formação. Para a classificação os solos são divididos em classes, os quais variam entre as características físicas, químicas e morfológicas. De acordo com o Sistema Brasileiro de Classificação de Solos - SBCS (2018), entre as classes de solos existentes no Brasil, predominam os Argissolos e Latossolos.

O solo é o principal substrato utilizado pelas plantas, o mesmo as sustenta e fornece nutrientes. Sendo constituído por três fases: através de sólidos, líquidos e gasosos. A parte solida está relacionada aos minerais e a matéria orgânica. Os minerais são formados principalmente por partículas inorgânicas que se encontram em diferentes fases de intemperismo e a formação da matéria orgânica se dá por meio de resíduos de organismos, como de animais e vegetais (SBCS, 2018).

A matéria orgânica influencia os atributos químicos, físicos e biológicos do solo, fornece nutrientes, favorece a troca catiônica, possui relação com a estrutura e densidade, auxilia na permeabilidade e na retenção de água, reduz o nível de compactação e atua como agente cimentante agregando as partículas (SILVA et al., 2019).

Além do material orgânico natural presente no solo, são incorporados adubos de variadas formas, como resíduos de animais e vegetais como fonte de matéria orgânica, aperfeiçoando assim as propriedades do solo e disponibilizando nutrientes as plantas (LIMA et al., 2015).

O esterco bovino é uma fonte de fertilizante orgânico, sua obtenção na maioria das vezes é dentro da própria propriedade. Uma vaca leiteira produz por dia em média de 45 quilos de esterco (PRIA, 2017).

Os suínos produzem dejetos que se não bem manejados podem causar prejuízos ao meio ambiente. No entanto, esses resíduos são constituídos por nutrientes que quando incorporados ao solo possuem importante papel no desenvolvimento das culturas, sendo então utilizados na agricultura como forma de insumo pelos agricultores. Dando assim destino correto a este produto e tornando o solo mais fértil com a finalidade de ofertar as plantas melhores condições de desenvolvimento (BARROS et al., 2019). 
As aves também produzem resíduos que como todos os outros devem ser manejados de modo adequado visando a proteção ambiental. Uma correta forma de destino à esses dejetos seria submete-los a compostagem, para que esses produtos oriundo das aves sejam tratados e reciclados para assim serem utilizados como adubo orgânico na agricultura (MAIA et al., 2014).

Alguns vegetais quando beneficiados também produzem resíduos assim como os animais. $O$ fruto do café quando passa pelo beneficiamento gera a palha de café, a qual possui nutrientes e pode ser utilizado como fertilizante na agricultura, devolvendo ao solo parte das substancias nutritivas retirada pelas plantas (ALVES, 2019).

A decomposição do material orgânico é um procedimento que transforma os elementos orgânicos em inorgânicos, sendo assim assimiláveis pelas plantas (MORÃO et al., 2017).

O uso de fertilizantes oriundos de materiais orgânicos, animal e/ou vegetal possibilita a redução do uso de fertilizantes sintéticos, proporciona a destinação sustentável destes resíduos, além de contribuir com a melhoria dos atributos químicos físicos e biológicos do solo (LIMA et al., 2015).

Sendo assim, o objetivo da pesquisa foi avaliar os efeitos da adição de diferentes materiais orgânicos no solo em relação a sua fertilidade e umidade do solo.

\section{MATERIAL E MÉTODOS}

A pesquisa foi realizada em uma área de $1.000 \mathrm{~m}^{2}$ que encontrava - se em pousio, localizada no Município de Campestre, Sul de Minas Gerais, coordenadas geográficas, latitude $21^{\circ} 42^{\prime} 10^{\prime \prime} \mathrm{S}$ e longitude $46^{\circ} 07^{\prime} 48^{\prime \prime} \mathrm{O}$, altitude de $1.092 \mathrm{~m}$ Google Earth (2020), durante os meses de Março/2020 a Junho/2020. De acordo com Alvares et al. (2013), o clima é classificado como clima cfb, o qual é observado em apenas 2,6\% do território brasileiro sendo a principal ocorrência desse clima é do sul de Minas (Serra da Mantiqueira) e parte do Rio de Janeiro e Espírito Santo até o Rio Grande do Sul (Planalto das Araucárias) e de acordo com Climate-Data.Orgwebsite (2020), a temperatura média anual é de $18,9^{\circ} \mathrm{C}$ e índice pluviométrico de $1.609 \mathrm{~mm}$.

Segundo os dados meteorológicos da estação online, Sismet Cooxupé (2020), o Município de Campestre - MG, no período de março/2020 a junho/2020, apresentou 
temperaturas médias de $18,1^{\circ} \mathrm{C}$, precipitação pluviométrica acumulada no período de 7,2 mm com média de 1,8mm e umidade relativa do ar média de $78,2 \%$ conforme a tabela 1 .

Tabela 1. Dados climatológicos do Município de Campestre - MG, de março/2020 a junho/2020.

\begin{tabular}{cccccc}
\hline & Março & Abril & Maio & Junho & Média \\
\hline $\mathrm{T} .{ }^{\circ} \mathrm{C}$ (máxima) & 26,4 & 25,2 & 22,2 & 23,9 & 24,4 \\
\hline $\mathrm{T} .{ }^{\circ} \mathrm{C}$ (mínima) & 16,9 & 14,9 & 10,9 & 8,6 & 12,8 \\
\hline $\mathrm{T} .{ }^{\circ} \mathrm{C}$ (média) & 20,9 & 19,4 & 16,3 & 16,1 & 18,1 \\
\hline $\begin{array}{c}\text { Precipitação } \\
\text { pluviométrica (mm) }\end{array}$ & 5,8 & 0,8 & 0,5 & 0,1 & 1,8 \\
\hline $\begin{array}{c}\text { Umidade relativa do } \\
\text { ar média (\%) }\end{array}$ & 81,9 & 81,1 & 76,8 & 73,1 & 78,2 \\
\hline
\end{tabular}

Fonte: Sismet Cooxupe, 2020.

A área em estudo é classificada segundo o SBCS (2018) como Latossolo Vermelho Amarelo e segundo os resultados obtidos por meio da análise granulométrica, apresenta textura média, com $8 \%$ de areia, $67 \%$ de silte e $25 \%$ de argila.

Em março/2020 foi realizado a aração e gradagem antes da implantação do experimento. Logo após, com trado holandês foi realizado a coleta de 20 sub amostras de solo na profundidade de $0-20 \mathrm{~cm}$, que posteriormente foram misturadas e resultando em 1 amostra composta de toda área. Sendo esta encaminhada ao laboratório Fertilidade do solo o qual passou pela metodologia de IAC, de acordo com Raij et al, (2001), onde foi realizado a avaliação dos parâmetros químicos referentes a fertilidade inicial do solo, conforme tabela 2.

Tabela 2. Resultado da fertilidade inicial do solo $0-20 \mathrm{~cm}$.

\begin{tabular}{lllllllll}
\hline $\mathrm{pH}$ & $\mathrm{MO}$ & $\mathrm{P}$ & $\mathrm{K}$ & $\mathrm{Ca}$ & $\mathrm{Mg}$ & $\mathrm{V}$ & $\mathrm{Al}$ & $\mathrm{m}$ \\
\hline $\mathrm{CaCl}_{2}$ & $\mathrm{~g} / \mathrm{dm}^{3}$ & $\mathrm{mg} / \mathrm{dm}^{3}$ & $\mathrm{mmolc} / \mathrm{dm}^{3}$ & $\mathrm{mmolc} / \mathrm{dm}^{3}$ & $\mathrm{mmolc} / \mathrm{dm}^{3}$ & $\%$ & $\mathrm{mmolc} / \mathrm{dm}^{3}$ & $\%$ \\
\hline 6,3 & 32 & 45 & 5,6 & 23 & 13,9 & 52 & 5 & 1 \\
\hline \multicolumn{7}{c}{ Métodos de extração: $\mathrm{P}:$ Resina $\mathrm{K}, \mathrm{Ca}, \mathrm{Mg}: \mathrm{NH}_{4} \mathrm{Cl}}$.
\end{tabular}

Após este processo, ocorreu a demarcação das parcelas, utilizando uma trena métrica as parcelas foram demarcadas com estacas de madeira e identificadas com placas. 
Em seguida foi realizado a instalação do experimento, onde ocorreu a aplicação do material orgânico no solo, realizada manualmente.

O experimento foi composto de cinco tratamentos com as seguintes fontes de material orgânico e concentrações: T1: esterco bovino 40 ton ha ${ }^{-1}$, T2: esterco de aves 5 ton ha-1 ${ }^{-1}$ T3: esterco de suíno 53 ton ha-1 ${ }^{-1}$ T4: palha de café 30 ton ha ${ }^{-1}$ e T5: tratamento controle sem adição de material orgânico 0 ton ha ${ }^{-1}$ (testemunha), dosagem de material orgânico (RIBEIRO et al., 1999). O delineamento experimental adotado foi o delineamento em blocos casualizados - DBC. Em cada tratamento foram realizadas 5 repetições, sendo cada parcela experimental constituída de $1 \mathrm{~m}^{2}$, distantes uma das outras de $1 \mathrm{~m}$ em todas as direções, resultando em 25 parcelas experimentais.

Em junho/2020, 90 dias após a aplicação dos tratamentos, foram retiradas 5 sub amostras de solo de cada parcela experimental para realizar análise da fertilidade e avaliação do teor de água.

Para analisar a fertilidade do solo foram retiradas amostras de solo nas camadas 0 $20 \mathrm{~cm}$ com o trado holandês, 5 sub amostras de cada parcela experimental foram coletadas e posteriormente misturadas resultando em 1 amostra composta para cada repetição, onde foram encaminhadas ao laboratório de fertilidade do solo.

As variáveis analisadas foram a fertilidade do solo, avaliada através da análise química do solo pela metodologia de IAC, de acordo com Raij et al, (2001) e a umidade do solo, pelo método gravimétrico.

O teste de umidade foi realizado através do método gravimétrico de acordo com a metodologia de Assunção, Krzyzanowski e Oliveira Neto (2010), onde as amostras de solos foram coletadas na profundidade de $0-20 \mathrm{~cm}$ e armazenadas em recipientes de alumínio com capacidade de 340 gramas cada, no qual foram identificadas de acordo com cada tipo de solo que armazenavam. Posteriormente, estas amostras foram colocadas sobre folhas de papel toalha e utilizando uma balança digital SF - 400, foi realizado a pesagem de 300 gramas desta amostra para realizar o teste. Após este processo, as 300 gramas de solo foram transferidas para um recipiente de vidro e levado ao micro-ondas Electrolux MTD30, com intervalo de tempo de 2 minutos, que após passou pela pesagem por meio da balança digital SF - $400 \mathrm{com}$ intuito de analisar quanto de umidade o solo tinha perdido. Todas as amostras contidas nas latas de alumínio passaram por todo este processo até o momento onde seu peso ficou constante. 
Os resultados levantados foram submetidos à análise de variância e a comparação das médias feitas pelo teste de Scott-Knott, a 5\% de probabilidade, ambos utilizando 0 software SISVAR ${ }^{\circledR}$ (FERREIRA, 2014).

\section{RESULTADOS E DISCUSSÃO}

Após 90 dias da aplicação dos compostos orgânicos, foi realizado a coleta das amostras de solo na camada de $0-20 \mathrm{~cm}$ para a análise dos parâmetros de fertilidade do solo e os resultados obtidos foram submetidos a análise estatística, conforme podemos observar os resultados na tabela 3 .

Tabela 3. Efeito do material orgânico na fertilidade do solo.

\begin{tabular}{cccccccc}
\hline & Unidade & $\begin{array}{c}\text { Esterco } \\
\text { Suíno }\end{array}$ & $\begin{array}{c}\text { Esterco } \\
\text { Bovino }\end{array}$ & $\begin{array}{c}\text { Esterco de } \\
\text { Aves }\end{array}$ & $\begin{array}{c}\text { Palha } \\
\text { de Café }\end{array}$ & Testemunha & CV\% \\
\hline $\mathrm{MO}$ & $\mathrm{g} / \mathrm{dm}^{3}$ & $40 \mathrm{~A}$ & $41 \mathrm{~A}$ & $40 \mathrm{~A}$ & $40 \mathrm{~A}$ & $33 \mathrm{~B}$ & 11,4 \\
$\mathrm{P}$ & $\mathrm{mg} / \mathrm{dm}^{3}$ & $83 \mathrm{~A}$ & $71 \mathrm{~A}$ & $80 \mathrm{~A}$ & $28 \mathrm{~B}$ & $32 \mathrm{~B}$ & 15,36 \\
$\mathrm{~K}$ & $\mathrm{mmolc} / \mathrm{dm}^{3}$ & $5,2 \mathrm{~A}$ & $4,6 \mathrm{~B}$ & $4,8 \mathrm{~B}$ & $6,4 \mathrm{~A}$ & $4,2 \mathrm{C}$ & 18,6 \\
$\mathrm{Ca}$ & $\mathrm{mmolc} / \mathrm{dm}^{3}$ & $33 \mathrm{~B}$ & $44 \mathrm{~A}$ & $39 \mathrm{~A}$ & $33 \mathrm{~B}$ & $28 \mathrm{C}$ & 9,4 \\
$\mathrm{Mg}$ & $\mathrm{mmolc} / \mathrm{dm}^{3}$ & $16 \mathrm{~B}$ & $22 \mathrm{~A}$ & $14 \mathrm{~B}$ & $12 \mathrm{~B}$ & $10 \mathrm{C}$ & 8,4 \\
$\mathrm{H}+\mathrm{Al}$ & $\mathrm{mmolc} / \mathrm{dm}^{3}$ & $53 \mathrm{~A}$ & $45 \mathrm{~B}$ & $59 \mathrm{~A}$ & $56 \mathrm{~A}$ & $60 \mathrm{~A}$ & 7,6 \\
$\mathrm{H}$ & $\mathrm{mmolc} / \mathrm{dm}^{3}$ & $53 \mathrm{~A}$ & $45 \mathrm{~B}$ & $59 \mathrm{~A}$ & $56 \mathrm{~A}$ & $60 \mathrm{~A}$ & 7,6 \\
$\mathrm{SB}$ & $\mathrm{mmolc} / \mathrm{dm}^{3}$ & $54,2 \mathrm{~B}$ & $70,6 \mathrm{~A}$ & $57,8 \mathrm{~B}$ & $51,4 \mathrm{~B}$ & $42,2 \mathrm{C}$ & 16,74 \\
$\mathrm{~T}$ & $\mathrm{mmolc} / \mathrm{dm}^{3}$ & $107,2 \mathrm{~A}$ & $115,6 \mathrm{~A}$ & $116,8 \mathrm{~A}$ & $107,4 \mathrm{~A}$ & $102,2 \mathrm{~B}$ & 8,36 \\
$\mathrm{~V}$ & $\%$ & $51 \mathrm{~A}$ & $61 \mathrm{~A}$ & $50 \mathrm{~A}$ & $48 \mathrm{~B}$ & $41 \mathrm{~B}$ & 12,34 \\
$\mathrm{~B}$ & $\mathrm{mg} / \mathrm{dm}^{3}$ & $0,37 \mathrm{~A}$ & $0,23 \mathrm{~B}$ & $0,19 \mathrm{~B}$ & $0,34 \mathrm{~A}$ & $0,45 \mathrm{~A}$ & 8,86 \\
$\mathrm{Fe}$ & $\mathrm{mg} / \mathrm{dm}^{3}$ & $107 \mathrm{~A}$ & $76 \mathrm{~B}$ & $73 \mathrm{~B}$ & $79 \mathrm{~B}$ & $97 \mathrm{~A}$ & 18,7 \\
$\mathrm{Mn}$ & $\mathrm{mg} / \mathrm{dm}^{3}$ & $24,6 \mathrm{~A}$ & $22,5 \mathrm{~A}$ & $16,4 \mathrm{~B}$ & $17,8 \mathrm{~B}$ & $16,3 \mathrm{~B}$ & 21,35 \\
$\mathrm{Zn}$ & $\mathrm{mg} / \mathrm{dm}^{3}$ & $3,9 \mathrm{~A}$ & $2,9 \mathrm{~A}$ & $3 \mathrm{~A}$ & $2,2 \mathrm{~B}$ & $2,3 \mathrm{~B}$ & 12,35 \\
$\mathrm{~S}$ & $\mathrm{mg} / \mathrm{dm}^{3}$ & $27 \mathrm{~A}$ & $19 \mathrm{~B}$ & $15 \mathrm{~B}$ & $17 \mathrm{~B}$ & $19 \mathrm{~B}$ & 8,86 \\
\hline
\end{tabular}

Métodos de extração: P: Resina; $\mathrm{K}, \mathrm{Ca}, \mathrm{Mg}: \mathrm{NH}_{4} \mathrm{Cl}$; B: água quente; $\mathrm{Fe}, \mathrm{Mn}, \mathrm{Zn}$ : DTPA; S: Fosf. Cálcio.

* Médias seguidas pelas letras diferentes diferem estatisticamente pelo teste de Scott-Knott, a 5\% probabilidade.

Os teores de Matéria Orgânica do Solo (MOS), onde receberam aplicação de materiais orgânicos se mostraram estatisticamente superiores a testemunha, tendo um 
incremento de $25 \%$ comparado ao resultado da amostragem inicial e testemunha após 90 dias.

De acordo com Araújo et al., (2020), a matéria orgânica do solo é estimada através do carbono orgânico, sendo necessário realizar a determinação do carbono o qual é multiplicado pela constante de 1,724 assim é obtido o teor de MO do solo.

Silva (2018) observou que ao realizar adubação do solo com esterco bovino, ocorreu um aumento linear do carbono orgânico presente no solo, proporcionando ampliação dos agregados e da porosidade, além da redução de densidade, sendo que estes resultados permaneceram mesmo após a aplicação deste material orgânico ter sido interrompido por dois anos em solo que passou anualmente por manejos mecânicos.

No parâmetro fósforo $(P)$, o tratamento com a aplicação de esterco suíno apresentou os teores mais elevados, seguido pelo esterco de aves e bovino, os quais foram superiores estatisticamente a testemunha e palha de café, quando comparados a amostragem inicial e a testemunha, tais tratamentos proporcionaram uma elevação importante nos teores deste nutriente no solo.

Algumas formulações de rações fornecidas aos suínos possuem nutrientes em excesso, os quais os animais não conseguem absorver, sendo então excretadas em suas fezes e urinas. Assim, os dejetos suínos são concentrados em nutrientes, principalmente de nitrogênio, potássio e fosforo (BARROS et al. 2019).

O fósforo é usado pelas culturas para alcançar ganho de produtividade (MARTINHÃO, 2011). Sendo assim, se faz necessário a presença deste elemento no solo e umas das formas seria por meio do acúmulo de matéria orgânica nas camadas mais superficiais, pois o material orgânico melhora a eficiência deste nutriente.

O elemento potássio $(K)$, o tratamento com aplicação de palha de café forneceu o teor mais elevado, seguido do suíno, superiores estatisticamente a aves e bovinos e superiores estatisticamente a testemunha.

Franco Junior e Novais (2017), em sua pesquisa utilizaram variadas formas de material orgânico para avaliar o crescimento inicial da cultura do café arábica da cultivar Mundo Novo, obtiveram o resultado onde o esterco bovino contribuiu com acréscimo de $63,2 \%$, o esterco bovino+palha de café em $56,87 \%$, a palha de café em $54,55 \%$ em relação a testemunha para a avaliação da altura do cafeeiro

A composição média da palha de café é de 0,5 a $1 \%$ de nitrogênio, 1 a $3 \%$ de fósforo e 25 a $35 \%$ de potássio, também possui teores significativos de micronutrientes 
(SANTINATO et al., 2020), assim sendo estes níveis de K podem ser a razão para elevação da fertilidade deste no solo.

No parâmetro cálcio (Ca), o tratamento com aplicação de esterco bovino apresentou os teores mais elevados, seguido do aves, suíno e a palha de café e superiores estatisticamente a testemunha. Raij et al. (1996), descreve que a composição média do esterco bovino fresco é de 2 gr de Cálcio para cada kg de esterco, tal concentração, permite o incremento destes níveis ao solo, com a aplicação deste.

Silva (2018) em sua pesquisa avaliou o efeito de diferentes doses de esterco bovino em relação aos atributos químicos e físicos do solo. Os tratamentos eram constituídos de diferentes dosagens de esterco bovino e foram aplicados no solo anualmente durante o período de 2011 a 2015. De acordo com os resultados obtidos, o autor observou que o nível de cálcio presente no solo aumentou de forma linear em relação as doses de esterco bovino utilizado, pois em 2011/2012 o teor médio de cálcio era de 27,2 mmocl/ $\mathrm{dm}^{-3}$ em 2014/2015 o teor médio era de $41,0 \mathrm{mmocl} / \mathrm{dm}^{-3}$.

Os níveis de Magnésio (Mg) no solo, o tratamento com aplicação de esterco bovino apresentou os teores mais elevados, superior estatisticamente ao suíno, aves e palha de café e superiores estatisticamente a testemunha.

Silva (2018), também observou nos resultados obtidos em seu experimento que houve aumento no nível de magnésio com o uso do esterco bovino, sendo que no período de 2011/2012 o teor médio de magnésio era de 20,2 mmocl/ $\mathrm{dm}^{-3}$ e em 2014/2015 o teor médio era de $21,1 \mathrm{mmocl} / \mathrm{dm}^{-3}$.

Nos parâmetros de acidez $(\mathrm{H}+\mathrm{Al})$ e $(\mathrm{H})$, teores baixos destes elementos no solo proporcionam melhores condições de desenvolvimento das plantas, pois o $\mathrm{Al}^{+++}$no solo é toxico. Segundo Ferreira, Moreira e Rassini (2006), no Brasil a produção de grãos é limitada pela ação do alumínio no solo, fazendo com que as plantas apresentem crescimento radicular reduzido, além de atingir sua divisão celular e reduzir o potencial da planta em absorver nutrientes e água do solo. O esterco bovino, se apresentou como sendo o tratamento que menos disponibilizou esses elementos.

Segundo Sobral et al., (2015), acidez ativa é quando o hidrogênio se encontra na forma $\mathrm{H}+$ na solução do solo e a acidez potencial é formada pela acidez trocável e acidez não trocável, o qual é simbolizada por $\mathrm{H}+\mathrm{Al}$. 
Silva (2018) ainda observou em seu experimento que após realizar adubação com esterco bovino a acidez potencial diminuiu e ao interromper a aplicação deste esterco no solo, os teores de hidrogênio e alumínio não aumentaram.

No parâmetro soma de bases (SB), o tratamento com aplicação de esterco bovino apresentou os teores mais elevados, superior estatisticamente a aves, suíno, palha de café e superiores estatisticamente a testemunha.

A soma de bases é composta por $\mathrm{Ca}+\mathrm{Mg}+\mathrm{K}$ e em algumas condições a presença significativa também de Sódio ( $\mathrm{Na}$ ). Silva (2018), também notou em seu experimento que todos esses elementos se elevaram com aplicação do esterco bovino no solo, resultando assim no aumento do teor da soma de bases.

A capacidade de troca catiônica T, (CTC potencial) do solo, todos os tratamentos se mostraram estatisticamente superiores a testemunha.

De acordo com Santos (2021), A CTC, capacidade de troca de cátions, quanto mais alta, maior será a fertilidade do solo, pois a CTC onde a mesma é dotada de cargas negativas e assim pode reter cátions como cálcio $\left(\mathrm{Ca}^{2+}\right)$, magnésio $\left(\mathrm{Mg}^{2+}\right)$, potássio $\left(\mathrm{K}^{+}\right)$, entre outros, estando relacionada com a disponibilidade em que o solo possui de armazenar e posteriormente disponibilizar nutrientes as plantas. Sendo assim, a CTC afeta diretamente a fertilidade do solo, pois o aumento da CTC pode elevar a sua fertilidade. Porém, para isto acontecer é preciso aumentar a superfície especifica do solo para que mais nutrientes possam ser retidos, sendo que uma das formas de ampliar este potencial é elevando o teor de matéria orgânica no solo. Silva (2018) observou que ocorreu aumento da capacidade de troca catiônica no solo na medida que adicionou doses do esterco bovino.

No parâmetro saturação por base (V\%), o tratamento com aplicação de esterco bovino apresentou os teores mais elevados, seguido por suíno e aves e superiores estatisticamente a palha de café e a testemunha.

Também em seu experimento, Silva (2018), observou que o teor de saturação por base aumentou com aplicação do esterco bovino. No período de 2011/2012 o teor médio de saturação por base era de $68,8 \%$ e em $2014 / 2015$ o teor médio era de $69,0 \%$.

O micronutriente boro $(B)$, a testemunha forneceu estatisticamente teores superior quando se comparado aos teores fornecidos pelos tratamentos. Fernandes et al. (2013) em sua pesquisa, concluiu que a aplicação de esterco de aves em lavouras cafeeiras proporcionou a elevação dos teores de B no solo. 
O nutriente ferro $(\mathrm{Fe})$, o tratamento com aplicação de esterco suíno apresentou os teores mais elevados, seguido da testemunha e superiores estatisticamente a palha de café, bovino e aves.

O elemento manganês $(\mathrm{Mn})$, o tratamento com aplicação de esterco suíno apresentou os teores mais elevados, seguido pelo bovino e superiores estatisticamente a palha de café, aves e testemunha.

Os teores de zinco $(\mathrm{Zn})$ no solo, o tratamento com aplicação de esterco suíno apresentou os teores mais elevados, seguido do aves e bovino, os quais foram superiores estatisticamente a testemunha e palha de café.

De acordo com Silva et al. (2015), o ferro, manganês e zinco são nutrientes que estão presentes na constituição do esterco dos suínos, provenientes da dieta destes animais.

O macronutriente secundário enxofre $(\mathrm{S})$, o tratamento com aplicação de esterco suíno apresentou os teores mais elevados, superior estatisticamente ao bovino, testemunha, palha de café e aves.

Porém Silva et al., (2015), analisou em seu experimento que o esterco suíno não forneceu enxofre, pois este elemento está pouco presente neste resíduo.

Após a análise dos dados relacionados aos efeitos de diferentes fontes de material orgânico na umidade do solo, podemos observar na figura 1 os dados obtidos através do método gravimétrico em relação a umidade do solo.

Figura 1. Efeito do material orgânico no teor de umidade do solo.

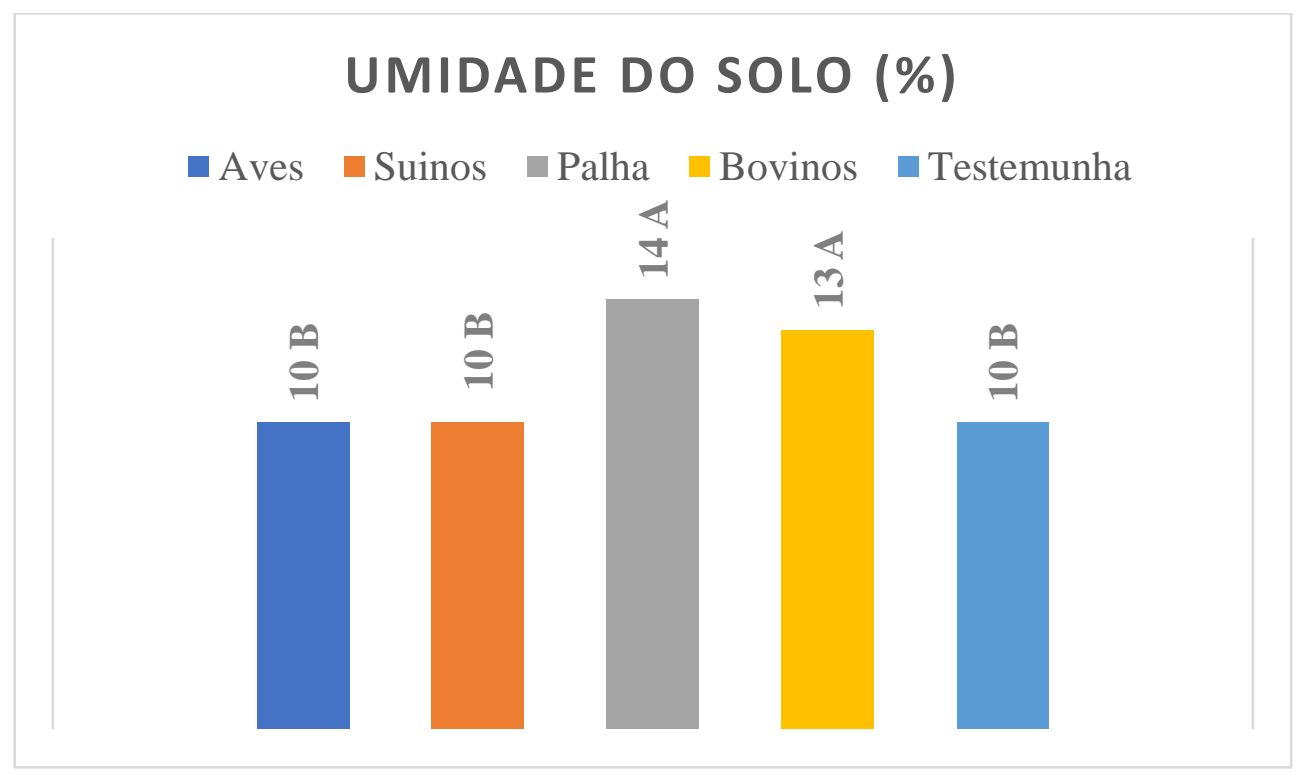

* Médias seguidas pelas letras diferentes diferem estatisticamente pelo teste de Scott-Knott, a 5\% probabilidade. 
O tratamento com aplicação de palha de café apresentou o teor mais elevado em relação a retenção de umidade no solo, seguido do esterco bovino.

Segundo Santinato et al., (2020), além da palha de café ser composta por nitrogênio, fosforo, potássio e demais nutrientes, Cooxupé (2021), relata que esta fonte de material orgânico contém carbono orgânico e também auxilia o solo a reter água.

Silva (2018), observou que ao adicionar esterco bovino ao solo, este material orgânico auxiliou na retenção de umidade.

O esterco de aves, suíno e testemunha reteram umidade, porem suas porcentagens foram inferiores.

\section{CONCLUSÃO}

A aplicação de material orgânico no solo promove elevação dos níveis de $\mathrm{MO}$ e nutrientes do solo, influenciando positivamente os teores nutricionais e os atributos químicos do solo, em relação a armazenamento de água no solo a aplicação da palha de café e esterco bovino resultaram em maiores níveis de retenção de umidade.

\section{REFERENCIAS}

ALVARES, C.A.; STAPE, J.L.; SENTELHAS, P.C.; GONÇALVES, J.L.M.; SPAROVEK, G. Köppen's climate classification map for Brazil. Meteorologische Zeitschrift, Sttutgart, 22:711 728, 2013.

ALVES, E.S.V. Adubação de cobertura em cafeeiro jovem utilizando palha de café. Monte Carmelo - MG, 2019. Disponível em: <http://repositorio.fucamp.com.br/bitstream /FUCAMP/446/1/Adubacaocoberturacafeeiro.pdf>. Acesso em: 03 maio 2021.

ARAUJO, E.C.G. et al. Determinação do teor de carbono orgânico total em amostra vegetal pelo método volumétrico com diferentes volumes de ácido sulfúrico. Revista BIOFIX Scientific Journal. Paraná - PR, v. 5 n. 1 p. 50, 2020. Disponível em: <https://revistas.ufpr.br/biofix/article/view/67939/39226>. Acesso em: 29 out. 2021.

ASSUNÇÃO, G. M.; KRZYZANOWSKI, F. C.; OLIVEIRA NETO, W. Análise de lignina com diferentes massas de tegumento de soja utilizando método gravimétrico. Embrapa. Londrina - PR, 2010. Disponível em: https://www.embrapa.br/busca-de-publicacoes//publicacao/859324/analise-de-lignina-com-diferentes-massas-de-tegumento-de-sojautilizando-metodo-gravimetrico. Acesso em: 08 dez. 2021.

BARROS, E.C. et al. Potencial agronômico dos dejetos de suínos. EMBRAPA. Concórdia - SC, 1a edição, p.9,10 2019. Disponível em: <https://www.infoteca.cnptia.embra pa.br/infoteca/bitstream/doc/1117243/1/final9052.pdf >. Acesso em: 27 out. 2021. 
CLIMATE. DATA. 2020. Disponível em: <https://pt.climate-data.org/america-dosul/brasil/minas-gerais/campestre-176359/>. Acesso em 08 maio 2020.

COMISSÃO DE FERTILIDADE DO SOLO DO ESTADO DE MINAS GERAIS. Recomendações para o uso de corretivos e fertilizantes 1999 em Minas Gerais - 5a Aproximação. ANTÔNIO CARLOS RIBEIRO, PAULO TÁCITO GONTIJO GUIMARÃES, VICTOR HUGO ALVAREZ V., Editores. - Viçosa, MG, 1999. 359p.

COOPERATIVA REGIONAL DE CAFEICULTORES EM GUAXUPÉ (COOXUPÉ). A importância da palha de café para a nutrição do cafeeiro. Guaxupé - MG. Disponível em:<https://hubdocafe.com.br/a-importancia-da-palha-de-cafe-para-a-nutricao-docafeeiro/>. Acesso em: 30 out. 2021

FERNANDES, A.L.T, SANTINATO, F.; FERREIRA, R.T.; SANTINATO, R.; ADUBAÇÃO ORGÂNICA DO CAFEEIRO, COM USO DO ESTERCO DE GALINHA, EM SUBSTITUIÇÃO À ADUBAÇÃO MINERAL. Coffee Science, Lavras, v. 8, n. 4, p. 486-499 out./dez. 2013 Acesso:< http://www.sbicafe.ufv.br/bitstream/handle/123456789/8003/Coffe e\%20Science_v8_n4_p486-499_2013.pdf?sequence=1\&isAllowed=y

FERREIRA, D. F. Sisvar: um guia dos seus procedimentos de comparações múltiplas Bootstrap. Ciência e Agrotecnologia. Lavras, v.38, n. 2, p. 109-112, mar/abr. 2014. Disponível em: <https://www.scielo.br/scielo.php?script=sci_arttext\&pid=S1413$70542014000200001>$. Acesso em 12 jun. 2021

FERREIRA, R.P; MOREIRA, A; RASSINI, J.B. Toxidez de alumínio em culturas anuais. Embrapa. São Carlos - SP, p.07, 2006. Disponível em: https://www.infoteca.cnptia.embrapa.br/bitstream/doc/47901/4/Documentos63.pdf. Acesso em: 08 dez. 2021.

FRANCO JUNIOR, K.S, NOVAIS, A.W. Avaliação do crescimento inicial do cafeeiro com diferentes fontes de matéria orgânica. Congresso Brasileiro de Pesquisas Cafeeiras. Machado - MG, p.1,2, $2017 . \quad$ Disponível em: <http://www.sbicafe.ufv.br/bitstream/handle/123456789/9417/196_43-CBPC-2017.pdf?seq uence $=1$ \&isAllowed $=y>$. Acesso em 27 out. 2021

GOOGLE EARTH. Globo terrestre detalhado. Disponível em: $<$ https://earth.google.com/web/>. Acesso em 08 maio 2020.

LIMA, B.V. et al. A adubação orgânica e a sua relação com a agricultura e o meio ambiente. São Paulo, 2015.

MAIA, R.C. et al. Tecnologias disponíveis para o destino de resíduos das granjas de postura. CURSO DE ATUALIZAÇÃO EM AVICULTURA PARA POSTURA COMERCIAL, 11. Resumos...Jaboticabal - SP, 2014. Disponível em: <https://ainfo.cnptia.embrapa.br/digital/bitstream/item/122617/1/final7672.pdf>. Acesso em: 4 de maio de 2021. 
MARTINHAO, D. Pesquisas avaliam práticas para uso eficiente de fertilizantes fosfatados. EMBRAPA. Brasília - DF, 2011. Disponível em: <https://www.embrapa.br/busca-denoticias/-/noticia/18145226/pesquisas-avaliam-praticas-para-uso-eficiente-de-fertilizantesfosfatados->. Acesso em: 29 out. 2021.

MORÃO, P.P. et al. Decomposição de matéria orgânica vegetal e animal: um estudo comparativo. Campinas - SP, 2017.

PRIA, A.D. Esterco tratado vira fertilizante e evita contaminação de nascentes de água. Revista Globo Rural. Tomazina - PR, 2017.

RAIJ, B. Van et al. Análise Química para Avaliação da Fertilidade de Solos Tropicais. Campinas, Instituto Agronômico, 285p. 2001.

RAIJ, B. Van et al. (Ed.). Recomendações de adubação e calagem para o Estado de São Paulo. 2.ed. Campinas: Instituto Agronômico, 1996. (IAC. Boletim Técnico, 100).

SANTINATO, R. et al. Adubação orgânica com a palha de café. Santinato e Santinato Cafés. São Paulo - $\quad$ SP, 2020. Disponível em: $<$ https://santinatocafes.com/artigos/detalhe/5959/adubacao-organica-com-a-palha-decafe $>$. Acesso em: 29 out. 2021.

SANTOS, M.S. CTC do solo, o que é e qual sua importância. Mais Soja, Santa Maria RS, 2021. Disponível em:<https://maissoja.com.br/ctc-do-solo-o-que-e-e-qual-suaimportancia/>. Acesso em: 27 out. 2021.

SBCS. Sistema Brasileiro de Classificação de Solos. Embrapa. Brasília - DF, 5ํeição, 2018.

SILVA, A.A. et al. Fertilização com dejetos suínos: influência nas características bromatológicas da Brachiaria decumbens e alterações no solo. Revista Engenharia Agrícola. Jaboticabal - SP, v.35 n.2 p.258, 2015. Disponível em: < https://www.scielo.br/j/eagri/a/XSQwvBPVVgDTVk8PKn VRXwD/?lang=pt>. Acesso em: 28 out. 2021.

SILVA, C.M.; FRANÇA, M.T.; OYAMADA, G.C. Características da suinocultura e os dejetos causados ao ambiente. Revista eletrônica do UNIVAG. Capa n.12, p. 54, MT, 2015.Disponível em: <http://periodicos.univag.com.br/index.php/CONNECTIONLINE/arti cle/view/199/453>. Acesso em: 28 out. 2021.

SILVA, F. W. A. et al. Matéria orgânica e suas inter-relações com os atributos físicos do solo. In. SEABRA, G.(Org.). Terra Habitats Urbanos e Rurais. Ituiutaba: Barlavento, p. 255,263, 2019. Disponível em: <https://www.researchgate.net/profile/Jose-BeldsonRamos/publication/342065146_DIAGNOSTICO_DO_GERENCIAMENTO_DOS_RESIDU OS_SOLIDOS_EM_UMA_INSTITUICAO_FEDERAL_DE_ENSINO_PUBLICO_N̄O_ANO_ DE_2017/links/5ee04a7545851516e665900a/DIAGNOSTICO-DO-GERENCIAMENTODOS-RESIDUOS-SOLIDOS-EM-UMA-INSTITUICAO-FEDERAL-DE-ENSINO-PUBLICONO-ANO-DE-2017.pdf\#page=255>. Acesso em: 22 abr. 2021. 
SILVA, M.S. Efeitos de esterco bovino em atributos químicos e físicos do solo, produtividade de milho e créditos de nitrogênio. Jaboticabal - SP, p. 1-3 2018. Disponível em:<https://repositorio.unesp.br/bitstream/handle/11449/154592/silva_ms_dr_ jabo.pdf?sequence=3\&isAllowed=y>. Acesso em: 27 out. 2021.

SISMET COOXUPÉ. 2020. Disponível em: <http://sismet.cooxupe.com.br:9000/>. Acesso em 12 set. 2021.

SOBRAL, L.F. et al. Guia Prático para Interpretação de Resultados de Análises de Solo. EMBRAPA. Aracaju - SE, 1ำ Edição, $2015 . \quad$ Disponível em: <https://www.infoteca.cnptia.embrapa.br/infoteca/bitstream/doc/1042994/1/Doc206.pdf.> Acesso em: 30 out. 2021. 


\begin{abstract}
Soil is a resource of fundamental importance for agriculture, one of its functions being the balanced supply of nutrients to plants. One of the ways to make the soil sustainable is through the application of organic matter, which can be of animal or vegetable origin. The objective was to evaluate the effect of adding different organic materials to the soil in relation to its fertility and moisture. Conducted an initial analysis to analyze soil fertility. Then, the area was divided into plots and the treatments were applied, which consisted of 40 ton ha $^{-1}$ of cattle manure, 5 ton ha-1 of poultry manure, 53 ton ha ${ }^{-1}$ of swine manure, 30 ton ha ${ }^{-1}$ of coffee straw and 0 ton ha ${ }^{-1}$ organic matter (control), being these treatments organized in randomized blocks with 5 replications. After 90 days, samples were taken from this soil for fertility and moisture analysis. The treatments that most contributed to its fertility were swine and cattle waste, and the one that most retained moisture was coffee straw.
\end{abstract}

Keywords: Manure. Nutrients. Residue. Water retention.

\title{
RESUMEN
}

El suelo es un recurso de fundamental importancia para la agricultura, siendo una de sus funciones el aporte equilibrado de nutrientes a las plantas. Una de las formas de hacer sostenible el suelo es mediante la aplicación de materia orgánica, que puede ser de origen animal o vegetal. El objetivo fue evaluar el efecto de agregar diferentes materiales orgánicos al suelo en relación a su fertilidad y humedad. Realización de un análisis inicial para analizar la fertilidad del suelo. Luego, se dividió el área en parcelas y se aplicaron los tratamientos que consistieron en 40 ton ha ${ }^{-1}$ de estiércol bovino, 5 ton ha ${ }^{-1}$ de estiércol de aves, 53 ton ha- ${ }^{-1}$ de estiércol porcino, 30 ton ha ${ }^{-1}$ de paja de café y 0 ton ha ${ }^{-1}$ de materia orgánica (control), siendo estos tratamientos organizados en bloques aleatorios con 5 repeticiones. Después de 90 días, se tomaron muestras de este suelo para análisis de fertilidad y humedad. Los tratamientos que más contribuyeron a su fertilidad fueron los desechos porcinos y bovinos, y el que más retuvo la humedad fue la paja de café.

Palabras-clave: Estiércol. Nutrientes Residuo. Retención de agua. 


\section{LICENÇA DE USO}

Este é um artigo publicado em acesso aberto (Open Access) sob a licença Creative Commons Atribuição 4.0 Internacional (CC BY 4.0), que permite uso, distribuição e reprodução em qualquer meio, desde que o trabalho original seja corretamente citado. Mais informações em: http://creativecommons.org/licenses/by/4.0

\section{CONFLITO DE INTERESSES}

Os autores declaram que não há conflito de interesses neste trabalho.

\section{CONTRIBUIÇÕES AUTORAIS}

Autor 1: Responsável pela autoria do texto e análise de dados.

Autor 2: Responsável pela autoria do texto, revisão e análise de dados.

Autor 3: Responsável pela autoria do texto, revisão e análise de dados.

Autor 4: Responsável pela revisão e análise dos dados.

Autor 5: Responsável pela revisão.

\section{FINANCIAMENTO}

O presente trabalho não contou com apoio financeiro.

\section{COMO REFERENCIAR}

ALVES, Daniela Fernanda et al. Efeitos de diferentes fontes de material orgânico na fertilidade e umidade do solo. Revista Brasileira de Engenharia de Biossistemas (Tupã), v. 15, n. 4, p. 644-659, 2021. DOI:

http://dx.doi.org/10.18011/bioeng2021v15n4p644-659.

\section{RESPONSABILIBADE EDITORIAL}

Prof. Dr. Fernando Ferrari Putti ${ }^{1}$, Prof. Dr. Paulo Sérgio Barbosa dos Santos ${ }^{1}$, Prof. Dr. Eduardo Festozo Vicente ${ }^{1}$ e Prof. Dr. Diogo de Lucca Sartori ${ }^{1}$

1 Universidade Estadual Paulista "Júlio de Mesquita Filho", FCE - Faculdade de Ciências e Engenharia, Tupã, SP, Brasil. 